\title{
INNER LIMITS
}

Gayle $\mathbb{K}$. Horii

Space seems infinite and never-ending; free to accommodate material presence, energy, and thought existence. It sacrifices itself upon demand. When not saturated, it awaits filling; when open, it awaits enclosing. Space is the arena between the end and the beginning. It is a requirement for being, for without it, there would be no place to be. Where there was something, the removal of that something leaves space. It has temporary boundaries and when inevitably they dissolve, space once more regains its original place. Space expresses itself freely in the absolute absence of all things.

To accept an existence in an enclosed space for long periods requires an endless struggle with innate requirements; to move, to think, to feel, to act and to express; my desires to be. Walls of office towers and houses, restrictions of labels and identities, constraints of illnesses, barriers of age, bars of prejudice and judgement have all confined me to varying degrees over the past $44 \frac{1}{2}$ years. Space has proven an elusive entity. Still, I search it out with craving, and discovering any, revel in it, wallowing in its luxury. The freedom to choose, where, when, how long, and to what extent I wish to use it, to move freely into or out of any space will continue to be my path as long as time permits.

Time specifies the duration and the tempo of existence, of being. It continues whether one is conscious or unconscious; it flows on. Unlike space, it resists enclosure; rather, it is without even temporary capture. It restricts, 
permits, measures and records the continuous threads of all existence.

Hold a photograph of an infant in your left hand and in your right hand, hold another photograph of the infant after sixty-five years has passed. Can you identify the photo in your left hand with the one in your right hand as being of the same person. The thread of time is the measure of this person. Time is the invisible which binds yesterday to today and today to tomorrow.

In Krishnamurti's Talks In India (1953) the author states:

Though the mind tries to use the symbol (of eternity) to go beyond, obviously, it is still within the field of time, time being memory; what I remember of yesterday, today and tomorrow, is the process of time, is the process of thought.

My personal experience of time is of memory, for to experience is already passed.

Time sprints by when I act or think within my inner core of wishes. It passes slowly when I act out of obligation or duty, and distinctly crawls when waiting in anticipation. Time was once a joy to plan; now it is a curse, as I deny the confinement strung years ahead in time. Where time once meant sharing and the fullness of achievement and creation, it now means emptiness, for all is hollow when confined three thousand miles from those I love.

I cherish the memories of time in sensuous expressions, in contrasts and awareness: Christmas brunch toasting with cognac while a fat turkey browns in the oven and shrieks of delight sing out as favoured treasures are uncovered; the ecstasy in the eyes of my sons, Wayne and Arie, as they shared their inspirations and their triumphs with me; cherry blossoms floating onto grass-green carpets forming blankets thick with pink petals; twenty foot breakers pummelling the expanse of Sunset Beach, Oahu; the scent of sunshine on my lover's skin, the touch of his lips to mine; the honking of one hundred Canadian geese in formation against a blue-grey sky; the snowflakes and the wind exhilarating as I skied through winding, forested trails of 
Whistler Mountain; the warm glow of firelight on my face and arms, embracing the magic of romance, the passions of loving and being loved as time-honored dynamics.

Now, I serve time: existing in a white-washed, asylum called Prison for Women. Stricken from the records of society are the acts spanning forty-one years. A few short minutes - an act of uncontrollable rage - an act which erased another life - this act; this five minutes now calculates the quality of my time, and imposes the limits to my existence. The survival of my being will largely depend on my ability to hold tenuously to an ancient Chinese image: the winged horse - symbol of thought; that which transcends all barriers of space and time. 
